\title{
GeStÃo dos SERVIÇOS de ÁGUA E ESGOTO NOS MUNICÍPIOS de Campinas, Santo André, São José dos Campos e SANTOS, NO PERÍOdo de 1996 a 2000
}

\author{
The management of water and sewage services in Campinas, Santo \\ André, SÃo José dos Campos ANd SANTOS, from 1996 to 2000
}

\section{RITA DE CÁSSIA OGERA}

Engenheira Sanitarista pela PUCCAMP - M.Sc. em Recursos Hídricos e Saneamento pela UNICAMP. Doutora em Saúde Pública - área de concentração Saúde Ambiental pela USP. Engenheira da Secretaria Municipal

de Planejamento Urbano de São Paulo

\section{ARLINDo PhiLIPPI JR.}

Engenheiro Civil e Sanitarista pela USP. Doutor em Saúde Pública e Livre Docente em Política e Gestão Ambiental pela USP. Professor do Departamento de Saúde Ambiental da Faculdade de Saúde Pública da USP

Recebido: 31/05/04 Aceito: 14/10/04

\section{RESUMO}

Este trabalho tem como objetivo analisar a gestão dos serviços de água e esgoto nos Municípios de Campinas, Santo André, São José dos Campos e Santos, no período 1996 - 2000. Nos Municípios de Campinas e Santo André, a gestão desses serviços encontra-se na esfera de governo municipal, enquanto nos $\mathrm{Mu}$ nicípios de São José dos Campos e Santos, a gestão encontra-se na esfera de governo estadual. Os métodos adotados foram pesquisa bibliográfica, pesquisa documental, pesquisa descritiva e investigação explicativa fundamentada pela teoria, seguida de análise dos resultados. Políticas públicas e políticas de governo foram tomadas como parâmetros para analisar as diferenças na eficiência e na eficácia da gestão desses serviços. Como resultados foram apontadas características e diferenças na eficiência e na eficácia da gestão dos serviços de água e esgoto nos âmbitos municipal e estadual.

PALAVRAS-CHAVE: Gestão do saneamento, políticas públicas, políticas de governo.

\section{ABSTRACT}

This study intends to analyze the water and sewage services management in Campinas, Santo André, São José dos Campos and Santos, from 1996 to 2000. In Campinas and Santo André, the municipal government implements the management of these services. In São José dos Campos and Santos, it is a State-level operation. The methods used for this paper were bibliographic, descriptive, and documental researches, and a subsequent theoretical explanation followed by an analysis of the results. Public and government policies were used as parameters to analyze differences in efficiency and efficacy of those services managements. The results obtained show characteristics and differences between State-level and municipal-level managements of the water and sewage treatments.

KEYWORDS: Sanitation management, public policies, governmentpolicies.

\section{INTRODUÇÃO}

A estruturação dos serviços de água e esgoto e intervenções de saneamento ocorridas no Brasil é notadamente marcada por três grandes períodos: o primeiro, a partir da segunda metade do século XIX, quando estava em andamento o processo de industrialização e seus reflexos no país, e em que a implantação dos sistemas de saneamento ocorreu, juntamente com outros sistemas de infra-estrutura, como estradas de ferro, geração de energia, iluminação pública e transportes urbanos de um modo geral, dentre outros. Nessa época, houve favo- recimento do Estado, com o incentivo à formação de empresas privadas, visando garantir o modus capitalista e adotando, para tanto, a política de concessão de serviços públicos a empresas privadas estrangeiras. Esse período extinguiu-se em 1927, em decorrência da crise mundial da economia capitalista (Jorge, 1987; MPO, 1995, v. 7).

O segundo período teve início na década de 1930, marcada pela transformação do Estado brasileiro, que abandonou a oligarquia das terras e iniciou, em 1937, um período de centralização do governo, que levou a uma ditadura. Nesse tempo, as obras públicas foram implementadas basicamente com recursos públicos a fundo perdido. O Estado assumiu a execução e a gestão dos sistemas de serviços urbanos por meio desses investimentos públicos. As primeiras intervençōes do governo federal em saneamento foram iniciadas com a edição do Código das Águas, em 1934, o qual lhe dava o poder de fixar as tarifas. O Código das Águas, apesar de sua ótica voltada para uma política de produção de hidroeletricidade, foi de fundamental importância para a gestão pública do setor de saneamento, pois estabeleceu os primeiros instrumentos de controle do uso dos recursos hídricos. Ao longo desse perío- 
do, as empresas concessionárias estrangeiras foram nacionalizadas e estatizadas e os serviços de água e esgoto foram assumidos pelas prefeituras dos municípios. Para a implantação desses serviços em regióes menos desenvolvidas do país, o governo criou a Fundação de Serviços de Saúde Pública. Essa política em relação ao saneamento se estendeu até meados da década de 1960 (Jorge, 1987; MPO, 1995, v. 7).

Já o terceiro período, pós-1964, é marcado pela criação do Banco Nacional de Habitação - BNH, responsável pelo Sistema Financeiro da Habitação, que passou, em 1968, a se responsabilizar também pelo o Sistema Financeiro do Saneamento-SFS, instituindo então, em 1971, o Plano Nacional de Saneamento PLANASA. O Plano foi um instrumento que o governo federal criou para que os Estados brasileiros implementassem, em suas cidades, sistemas de abastecimento de água e de esgoto. Foram criadas, assim, Companhias Estaduais de Saneamento Básico às quais foram concedidos os sistemas de saneamento urbano. Com esta nova forma de gestão, os investimentos por parte do governo puderam ter condições de retorno, pois foram feitos a título de empréstimo.

O PLANASA exigia dos Estados a criação de companhias estaduais de saneamento, condição básica para a viabilização do Plano, sem o que os municípios não receberiam recursos financeiros do governo federal. Muitos municípios aderiram, outros não, pois decidiram manter a forma de gestão municipal dos serviços de saneamento básico, apesar das fortes pressōes políticas para aderirem ao plano (FUNASA, 1996). Em conseqüência do PLANASA, àquela época, 27 companhias estaduais foram criadas no país e os municípios concederam a gestão do saneamento aos Estados, por meio de contratos de concessão, com prazos de 20 a 25 anos.

Segundo Relatório da Conferência Nacional de Saneamento - CNS (1999), apesar de contradiçôes contidas no PLANASA, este pode ser considerado um dos planos mais bem sucedidos da administração pública brasileira, pois, "em pouco mais de 20 anos foi possível estender os serviços de abastecimento de água e esgoto sanitário para cerca de $70 \mathrm{mi}$ lhōes de pessoas" (CNS, 1999, p.17). No entanto, observam-se disparidades gritantes quando se compara o índice geral brasileiro de cobertura dos serviços de água e esgoto com os índices regionais.
A falta de adesão ao PLANASA por parte dos municípios de médio e grande porte, como também outros fatores, como o desemprego e conseqüentemente a queda salarial, levaram à extinção, em 1986, do BNH, executor do PLANASA, e a responsabilidade quanto ao financiamento do saneamento ficou a cargo da Caixa Econômica Federal. Depois da extinção do PLANASA, ocorreram reformas administrativas e os recursos financeiros foram repassados para as prefeituras e companhias estaduais, através de programas instituídos pelo governo federal. A fragilidade das políticas públicas e a precariedade dos serviços de saneamento no país, somada ao significativo crescimento populacional, principalmente nas grandes cidades, levaram o governo brasileiro a conceber, em 1992, o Projeto de Modernização do Setor de Saneamento PMSS.

Por outro lado, projetos de leis foram elaborados na tentativa de estabelecer políticas públicas nacionais para o saneamento, tais como, o Projeto de Lei $n^{\circ} 199$ de 1991, o Projeto de Lei no 266 de 1996. Em 2001, foi elaborado e discutido o Projeto de Lei 4147, porém sem sucesso efetivo.

Desde então, o Brasil não conta com políticas públicas nacionais para o saneamento básico, o que leva Estados e municípios a definições próprias de suas políticas públicas, podendo provavelmente estar desarticuladas, tanto em âmbito de governo como entre setores de planejamento.

Neste contexto, o Brasil vem administrando os serviços de abastecimento de água e esgotamento sanitário, pelos Estados por meio de companhias, mediante concessões municipais, e pelos municípios, por meio de administração municipal direta, ou autarquias, ou empresas públicas ou ainda assistidos pela Fundação Nacional de Saúde.

Em todas as regióes do Brasil, as companhias estaduais têm presença marcante. Entretanto, muitas delas ainda não conseguiram superar a crise econômica que se iniciou nos anos de 1980, principalmente devido às dificuldades em adequar os seus custos à arrecadação tarifária.

Em relação aos 5.507 municípios brasileiros (IBGE,* 2000), tem-se a comentar que, conforme dados da Associação Nacional dos Serviços Municipais de Saneamento-ASSEMAE (2000a, 2000b), 1.700 administram de forma lo- cal seus serviços de água e esgoto, sendo que a sua maioria pertence aos Estados de São Paulo e Minas Gerais e os 3.807 municípios restantes são administrados pelas companhias estaduais.

Na maioria dos municípios, os contratos de concessão ainda estão em vigor. No entanto, uma parcela significativa dos municípios está sem contrato ou com a concessão vencida. Destaque-se que alguns desses serviços sem concessão formalizada correspondem a capital de estado e municípios de grande porte, como São Paulo e Santos (SNIS, 1999).

Assim, o desafio deste trabalho é analisar a gestão dos serviços de água e esgoto em quatro municípios de grande porte do Estado de São Paulo, no período de 1996 a 2000, sendo eles: Campinas, Santo André, São José dos Campos e Santos. Nos Municípios de Campinas e Santo André, a gestão desses serviços encontra-se na esfera de governo municipal. Já nos Municípios de São José dos Campos e Santos, a gestão encontra-se na esfera de governo estadual. Dentro deste contexto pergunta-se:

- Há diferenças na eficiência e na eficácia da gestão desses serviços, quando se trata de esfera de governo estadual ou municipal; e na existência, ou não, de políticas públicas e políticas de governo que contemplem esses serviços?

- Em que aspectos e em que âmbito de governo estas diferenças se apresentam? Em relação a esses aspectos, são aqueles medidos pelos indicadores, tais como, população atendida por água, população atendida por esgotamento sanitário e aumento no tratamento de esgoto. Em relação ao âmbito desses serviços, procura-se focalizar a responsabilidade estadual e a municipal na gestão desses serviços.

- Existe correspondência entre o que é declarado nas leis com o que é efetivamente praticado pelos governantes e(ou) gestores desses serviços?

\section{MÉTODO}

O caminho percorrido para a consecução dos objetivos deste trabalho foi, primeiro, conhecer a gestão dos serviços de água e esgoto em cada um dos quatro municípios e as relaçōes entre as esferas de governo estadual e municipais, levantando indicadores que permitissem analisar a gestão municipal e estadual desses serviços naqueles municípios. Em seguida, passou-se a analisar as políticas públi-

\footnotetext{
* O Brasil passa a contar a partir de 2001 com 5.561 municípios (IBGE, 2002). Neste trabalho foi tomado como referencial - 5.507 municípios - existentes até 2000 (IBGE, 2000 ).
} 
cas relacionadas ao saneamento e as políticas públicas correlacionadas, de âmbito nacional, estadual e municipal. Finalmente, foram analisadas as políticas de governo de cada município, no período 1996 - 2000.

Neste sentido, os métodos adotados foram: seleção dos municípios, pesquisa bibliográfica, pesquisa documental, aplicação de questionários, investigação explicativa fundamentada pela teoria, seguida de análise dos resultados.

Dos documentos analisados, destacam-se as legislaçóes nacionais, estaduais e municipais em relação ao saneamento, saúde, meio ambiente, recursos hídricos bem como os planos plurianuais, as leis de diretrizes orçamentárias, as leis orçamentárias dos quatro municípios e do Estado de São Paulo, e os planos diretores de cada município. Dentre as leis estudadas, destacam-se a Constituição Federal, a Política Nacional de Meio Ambiente, a Política Nacional de Recursos Hídricos, a Política Nacional de Saúde, a Constituição Estadual de São Paulo, a Política Estadual de Saneamento de São Paulo e a Política de Recursos Hídricos do Estado de São Paulo.

Os dados qualitativos e quantitativos, obtidos por meio dos questionários, foram trabalhados alguns na forma de indicadores e outros como dados referenciais para a realização das análises, dando assim subsídios para interpretaçōes e conclusões sobre os serviços de água e esgoto dos municípios estudados.

Assim, o que é eficiência e eficácia? Para Michaelis (2002), Eficiência é "ação, capacidade de produzir um efeito" e Eficácia é "qualidade daquilo que produz o resultado esperado".

Já para Lima (2000), eficiência "tem a ver com os processos, procedimentos, rotinas, a forma de fazer bem as coisas, a utilização do tempo e dos recursos e a eficácia éo resultado da decisão acertada, a orientação das açôes, planos e programas na consecução dos objetivos (....) diz respeito ou depende da estratégia a ser seguida quanto ao uso do tempo, alocação de recursos (....)”.

Desse modo, definiu-se como parâmetros para medir a eficiência as diretrizes destacadas nos artigos das leis municipais cruzando - as com programas, projetos, atividades, obras e metas destacadas nos Planos Plurianuais, Leis de Diretrizes Orçamentárias, Leis Orçamentárias Anuais, Orçamentos Anuais e Planejamentos Estratégicos.

Observa-se, assim, que a análise realiza-se comparando políticas públicas com políticas de governo, identificando o que foi declarado em leis e o que foi praticado pelos governantes das prefeituras e dos gestores dos serviços de água e esgoto e resultados alcançados.

Já a eficácia na gestão dos serviços de água e esgoto se dá quando se tem resultado social, ou seja, quando a população usufrui a água e os serviços de esgoto, como nítida conseqüência de abrangência dos serviços, incluindo, cada vez mais, maior número de habitantes, tanto em termos de cobertura de água, como coleta e tratamento de esgoto. Em relação aos parâmetros definidos para medir eficácia foram as informaçōes originadas dos questionários e da pesquisa documental como: evolução da população atendida por coleta de esgoto em função da evolução da população urbana do município; evolução do volume de esgoto coletado em função da evolução do volume de esgoto tratado; evolução do investimento em sistema de esgoto em função da evolução da população urbana; evolução do número de economias de esgoto em função da evolução da população urbana; evolução da população atendida por água em função da evolução da população do município; evolução do número de economias ativas de água em função da evolução da população; e evolução do volume de água faturado em função da evolução da população urbana, cruzando-os com diretrizes destacadas nos artigos das leis orgânicas e dos planos diretores com programas, projetos, atividades obras e metas establelecidas nos Planos Plurianuais, Leis de Diretrizes Orçamentárias, Leis Orçamentárias Anuais, Orçamentos Anuais e Planejamentos Estratégicos.

Finalmente, as diretrizes destacadas das leis federal e estadual foram tomadas como parâmetros norteadores para a identificação das políticas públicas municipais e estaduais.

Como se vê, foram identificadas diretrizes das políticas públicas nacionais, estaduais e municipais voltadas ao saneamento básico, as quais foram comparadas com as políticas de governo estabelecidas para os 4 municípios no período de 1996-2000. Portanto, as políticas públicas e as políticas de governo foram tomadas como parâmetros de análise. Desse modo, para identificar as políticas de governo desse período, foram estudados os seguintes instrumentos: Plano Plurianual, Lei de Diretrizes Orçamentárias, Leis Orçamentárias Anuais, Orçamentos Anuais e Planejamentos Estratégicos.

\section{RESULTADOS E DISCUSSÃO}

A partir do método, ora, mencionado foram obtidas as informaçōes do sistema de abastecimento de água e do sistema de esgoto dos municípios, tais como índice de atendimento de água e esgoto, número de economias de água e esgoto, índice de tratamento de esgoto e investimentos nos sistemas de água e esgoto, apresentadas nas tabelas 1 a 4 .

Município de Campinas - A gestão dos serviços de água e esgoto é realizada no âmbito municipal, de forma indireta por meio de empresa de economia mista de capital aberto, responsável pela produção, tratamento e distribuição de água bem como a coleta, tratamento e disposição final do esgoto.

$\mathrm{Na}$ Lei Orgânica de Campinas, um ponto a ser destacado é o fato de deixar bem clara a priorização quanto à forma de organização e prestação dos serviços públicos, sendo que prioritariamente será por outorga às suas autarquias ou entidades paraestatais e, em seguida, por delegação a particulares, mediante concessão, permissão ou autorização, nos dois casos podendo ser centralizada ou descentralizada. Esta amarração na lei orgânica sobre a forma de prestação dos serviços públicos é um fator favorável para o município, na medida em que o setor privado vem de maneira gradativa atuando nos serviços de natureza pública.

O artigo 5० da Lei Orgânica diz respeito ao controle da poluição e à proteção ao meio ambiente e o artigo $8^{\circ}$ colocam que o município assegurará recursos para, no prazo de 10 anos da promulgação da lei orgânica de 1990, promover o tratamento de todo esgoto da cidade. Pois bem, comparando isso com os resultados identificados nas políticas de governos, Campinas apresenta uma evolução no índice de tratamento muito insignificante perante o volume de esgoto coletado, como pode ser observado na tabela 1 .

Ao destacar as diretrizes contidas na Lei Orgânica e no Plano Diretor de Campinas, e cruzando-as com os programas, projetos, atividades, obras e metas, das políticas de governo do município, puderam ser identificados pontos na eficiência e na eficácia da gestão em relação aos aspectos de esgoto e de água. Assim, com relação ao aspecto esgoto, tem-se que: a gestão municipal desse serviço mostrase eficiente na medida em que os órgãos gestores vêm estabelecendo e implementando programas, projetos e obras em 
consonância com a Lei Orgânica da cidade e o Plano Diretor.

No entanto, mostra-se ineficaz quanto aos resultados no aspecto tratamento de esgoto, pois, de acordo com a Lei Orgânica, o município deveria ter no ano 2000 a totalidade de seu esgoto tratado e, como pode ser observado na tabela $1, o$ índice desse tratamento ao longo dos anos vem crescendo de forma muito lenta, atingindo apenas em torno de $10 \%$ do que é coletado, ou seja, no ano de 1996 apenas $1,7 \%$ do esgoto coletado foi tratado, chegando no ano de $2000 \mathrm{com}$ $5,6 \%$ de tratamento, o que ainda é muito baixo, considerando-se principalmente que o número de economias ativas de esgoto aumentou em torno de $12 \%$, entre os anos de 1996 e 2000, passando de 263.763 economias ativas para 298.342 economias ativas no ano de 2000 , ver tabela 1. Outro fato a considerar é que a população da cidade vem crescendo a taxas de 1,5\% a.a., demandando infra-estrutura necessária a sustentabilidade da cidade.

Em relação ao indice de atendimento de esgoto, este passou de $86 \%$ no ano de 1996 para $88 \%$ no ano de 2000 , nesse sentido vem se mostrando eficaz. No entanto, $12 \%$ da população urbana de Campinas não atendida com rede coletora representam quase 100.000 habitantes desprovidos dessa instalação. Então, esse é um aspecto que merece maior atenção e investimentos dos gestores da cidade, pois, como pode ser observado nos resultados da tabela 1 , os investimentos no sistema de esgoto vêm diminuindo drasticamente. O gestor desse serviço deve ser mais eficaz no que tange à coleta e tratamento de esgoto, bem como ao monitoramento da quantidade de ligaçóes e de economias ativas de esgoto. Para tanto, é necessário que esse órgão gestor realize maiores investimento no sistema de esgoto e em medidas de educação ambiental, trabalhando a sociedade no sentido de mobilizá-la quanto à importância da disposição e tratamento adequados de seus efluentes, para a proteção da saúde e do meio ambiente. Assim, quanto ao tratamento, cabe ao órgão gestor tomar medidas mais eficazes no sentido de cumprir a lei orgânica da cidade, para que o esgoto gerado no município seja $100 \%$ coletado e tratado, a fim de recuperar e conservar os mananciais da cidade os quais, por sua vez, são considerados os mais poluídos do Brasil e do Estado de São Paulo, protegendo e promovendo a saúde da população Campineira.
Com relação aos pontos de eficiência e eficácia da gestão destacados na Tabela 1, ao aspecto água, observa-se que:

- Quanto à cobertura de água, $98 \%$ da população urbana é atendida, indo ao encontro das diretrizes da Lei Orgânica que diz respeito ao acesso universal de todos os munícipes às ações e serviços de promoção e proteção da saúde. A quantidade de economias ativas passou de 296.596 para 348.150 , ou seja, 51.554 economias ao longo de 5 anos. Se considerarmos que cada economia tem em média 3 pessoas, isso resulta em um atendimento em torno de 154.662 habitantes ao longo desses 5 anos, significando que o órgão gestor vem atendendo à demanda do crescimento populacional que girou em torno de 90.000 habitantes no período de 1996 a 2000.

Desse modo, com relação à eficiência e eficácia no aspecto de água, tem-se que: a gestão municipal desse serviço mostra-se eficiente, à medida que os órgãos gestores estabelecem programas, projetos e obras em consonância com a Lei Orgânica da cidade, tendendo à universalização desse serviço, pois se observa que $98 \%$ da cidade é atendida por esse serviço. Há que se comentar que, tendo o município 956.533 moradores na área urbana e que $98 \%$ dessa população é atendida com água, significa dizer que em torno de 19.000 habitantes são desprovidos de rede de água e que esse percentual vem se mantendo constante, o que pressupóe que o investimento tem sido para a manutenção e atendimento do crescimento vegetativo. Portanto, em relação à melhoria da eficácia desse serviço o órgão gestor deve investir na expansão do sistema, principalmente nas áreas que hoje são atendidas por torneiras coletivas e por caminhôes-pipa, para que um maior número de pessoas se beneficie da água encanada. Para tanto, deve buscar maior articulação e integração com as diretrizes de expansão urbana constantes no Plano Diretor da cidade e, conforme já estabelecido pela Lei Orgânica, em seu artigo 203, instituir um plano de saneamento em consonância com esse Plano Diretor.

Mostra-se também eficaz no que tange aos resultados alcançados em relação à evolução do volume faturado de água que, ao longo dos 5 anos, cresceu em torno de $4 \%$, através de recuperação das perdas com atuação em ligaçôes clandestinas e inadimplências de usuários.

Município de Santo André - A gestão dos serviços de água e esgoto é realiza- da no âmbito municipal, por meio de autarquia no status de órgão da administração direta, que tem, como funçōes, planejar, projetar e executar os serviços referentes ao sistema de abastecimento de água e coleta de esgoto, cuidar da drenagem da águas pluviais, proteger os mananciais, promover a educação ambiental, cuidar da defesa civil e do licenciamento ambiental no âmbito do município. $\mathrm{O}$ Serviço Municipal de Saneamento Ambiental - SEMASA compra água por atacado da Companhia de Saneamento Básico do Estado de São Paulo - SABESP, a qual é produzida no Município de São Paulo. Em relação ao sistema de esgoto, o SEMASA faz a coleta e a SABESP realiza o tratamento.

Um dos aspectos importantes e relevantes a destacar na Lei Orgânica de Santo André é o tratamento especial dado ao saneamento básico, salientando em seus artigos 206 e 210 açōes conjuntas e integradas com os municípios limítrofes e que o planejamento, controle e avaliação das ações de saneamento deverão contar com usuários domiciliares, comerciais e industriais, representantes dos trabalhadores, do Poder Legislativo e do Sistema Único de Saúde em nível municipal. Isso demonstra a abertura para a participação e também a visão de conjunto. Em seu artigo 212, coloca que compete ao $\mathrm{Mu}$ nicípio participar da formulação da política estadual de saneamento básico. Mostra mais uma vez a importância atribuída à questão da articulação das políticas públicas.

Da mesma maneira que a lei orgânica, o Plano Diretor reserva um capítulo especial para o saneamento, englobando o sistema de água, esgoto, drenagem, limpeza urbana e prevenção de zoonoses. No artigo 31, inciso 2, é salientado que, em função de o abastecimento de água e esgoto ser integrado ao sistema adutor metropolitano, o Poder Executivo poderá contratar a Companhia Estadual de Saneamento para o fornecimento de água potável, estabelecendo condições de quantidade, regularidade e qualidade. Nesse sentido, cabe ressaltar que o SEMASA compra água por atacado da SABESP e responsabiliza-se pela distribuição. Esse é um diferencial que merece ser ponderado quando da análise sobre eficácia na gestão desses serviços.

Ao destacar as diretrizes contidas na Lei Orgânica e no Plano Diretor de Santo André, e cruzando-as com os programas, projetos, atividades, obras e metas, contidas nas políticas de governo do municí- 
Tabela I - Informações sobre água, esgoto e população - período de 1996 a 2000

\begin{tabular}{|c|c|c|c|c|c|}
\hline \multirow{2}{*}{ Informação } & \multicolumn{5}{|c|}{ Campinas } \\
\hline & 1996 & 1997 & 1998 & 1999 & 2000 \\
\hline População total (hab.) (3) & 910.975 & 924.617 & 938.670 & 952.758 & 966.700 \\
\hline População urbana (hab.) (3) & 891.670 & 906.054 & 920.873 & 935.758 & 950.533 \\
\hline $\begin{array}{l}\text { Economias ativas de água } \\
\text { micromedidas (un.) (2) }\end{array}$ & 296.596 & 306.625 & 321.184 & 337.260 & 348.150 \\
\hline Economias ativas de esgoto (un.) (2) & 263.763 & 272.471 & 279.646 & 291.369 & 298.342 \\
\hline $\begin{array}{l}\text { Volume de água tratada } \\
\left.\text { produzido ( } \mathrm{m}^{3} / \mathrm{ano}\right)\end{array}$ & 112.164 .362 & 114.615 .745 & 111.146 .252 & 107.270.719 & 107.520 .307 \\
\hline Volume de água faturado (m³/ano) (1) & 78.257 .132 & 79.005 .622 & 79.145 .731 & 80.381 .466 & 81.213 .550 \\
\hline Volume de esgoto coletado ( $\left.\mathrm{m}^{3} / \mathrm{ano}\right)$ & 66.786 .758 & 67.340 .750 & 66.177 .596 & 52.773 .514 & 51.694 .874 \\
\hline Volume de esgoto tratado ( $\left.\mathrm{m}^{3} / \mathrm{ano}\right)$ & 1.124 .099 & 1.401 .235 & 1.545 .869 & 2.530 .932 & 2.910 .090 \\
\hline Índice de atendimento de água (\%) (1) & 97,6 & 97,8 & 98,0 & 98,0 & 98,0 \\
\hline Índice de atendimento de esgoto (\%) (1) & 86,0 & 86,0 & 89,0 & 89,0 & 88,0 \\
\hline Índice de esgoto tratado (\%) (1) & 1,7 & 2,1 & 2,3 & 4,8 & 5,6 \\
\hline $\begin{array}{l}\text { Receita operacional dos serviços de água } \\
\text { (R\$/ano) (1) }\end{array}$ & $69.581 .000,00$ & $73.548 .000,00$ & $75.824 .000,00$ & $80.784 .000,00$ & $83.865 .000,00$ \\
\hline $\begin{array}{l}\text { Despesa operacional dos serviços de água } \\
\text { (R\$/ano) (1) }\end{array}$ & $104.523 .000,00$ & $76.136 .000,00$ & $74.057 .000,00$ & $73.205 .000,00$ & $75.525 .000,00$ \\
\hline $\begin{array}{l}\text { Investimentos no sistema de água } \\
(\mathrm{R} \$ / \mathrm{ano}) \text { (2) }\end{array}$ & 11.508 .542 & 7.153 .076 & 1.691 .366 & 1.542 .515 & 1.309 .020 \\
\hline $\begin{array}{l}\text { Investimentos no sistema de esgoto } \\
\text { (R\$/ano) (2) }\end{array}$ & 14.182 .318 & 6.836 .064 & 17.452 .060 & 19.334 .953 & 4.662 .356 \\
\hline
\end{tabular}

Fontes: (1)Sociedade de Abastecimento de Água e Saneamento de Campinas - Sanasa; (2) Sistema Nacional de Informação sobre Saneamento - SNIS; (3) Instituto Brasileiro de Geografia e Estatística - IBGE.

pio, foram identificados pontos na eficiência e na eficácia da gestão em relação aos aspectos de esgoto e de água. Assim, com relação à eficiência e eficácia da gestão de Santo André quanto ao aspecto esgoto, temse que: a gestão municipal desse serviço mostra-se eficiente, à medida que os órgãos gestores vêm estabelecendo programas, projetos e atividades em consonância com a Lei Orgânica da Cidade e com o Plano Diretor.

Mostra-se eficaz em relação ao atendimento de esgoto, mesmo tendo apresentado uma variação nesse índice de cobertura, que passou de $96 \%$ para $93 \%$, pois é um índice alto de atendimento se comparado, por exemplo, com Campinas. No entanto, essa evolução negativa indica que o órgão gestor está deixando de priorizar as questóes relacionadas a esse sistema, considerando principalmente que a evolução da população vem diminuindo. Isso pode ser notado também no que tange aos os recursos financeiros que vem sendo aplicado no sistema de esgoto, ver Tabela 2.
Quanto ao indice de tratamento de esgoto, não é possível dizer se o SEMASA, órgão gestor, está sendo eficaz, pois o tratamento é realizado pela SABESP na ETE Estação de Tratamento de Esgoto ABC, portanto, considerado, para efeito deste trabalho, como "zero".

Quanto ao aspecto água, tem-se que essa gestão é eficaz, se considerada do ponto de vista do índice de atendimento, que é de $96 \%$. No entanto, esse índice passou de $99 \%$ para $96 \%$, e os investimentos no sistema de água também se mostraram decrescentes. Esta é uma situação que merece ser destacada uma vez que em Santo André o crescimento populacional tem sido negativo, passou de 632.493 habitantes para 625.564 habitantes.

Como o SEMASA realiza gestão integrada dessas questôes com as de drenagem, resíduos sólidos, meio ambiente e defesa civil, provavelmente as prioridades de investimentos foram direcionadas nestas outras áreas, ou seja, utilizando-se de subsídios cruzados entre elas.
Município de São José dos Campos - A gestão dos serviços de água e esgoto é realizada pela Companhia Estadual de Saneamento, de forma indireta, através de concessão.

Na Lei Orgânica de São José dos Campos, há que se destacar a importância atribuída à realização de ações integradas no que tange às questóes do controle ambiental, da saúde e de saneamento, conforme diz seu artigo 277: 'É de competência do Município, exercida pela Secretaria Municipal de Saúde, planejar e executar as açôes de controle do meio ambiente e de saneamento básico, no âmbito do Município, em articulação com os demais órgãos governamentais" (art.277). Assim, quanto a essa integração, as investigações documentais mostraram que há um efetivo intercâmbio e participação da administração municipal no desenvolvimento dos programas de saneamento básico. Tal afirmação pode ser notada ao se observar as diretrizes apontadas nos planos plurianuais e nos orça- 
Tabela 2 - Informações sobre água, esgoto e população - período de 1996 a 2000

\begin{tabular}{|c|c|c|c|c|c|}
\hline \multirow[t]{2}{*}{ Informação } & \multicolumn{5}{|c|}{ Santo André } \\
\hline & 1996 & 1997 & 1998 & 1999 & 2000 \\
\hline População total (hab.) (2) & 632.493 & 636.091 & 639.949 & 644.135 & 648.121 \\
\hline População urbana (hab.) (2) & 632.493 & 636.091 & 639.949 & 644.135 & 648.121 \\
\hline Economias ativas micromedidas (un.) (1) & 182.330 & 218.596 & 224.282 & 226.907 & 236.972 \\
\hline Economias ativas de esgoto (un.) (1) & 175.890 & 211.802 & 217.733 & 225.793 & 230.013 \\
\hline $\begin{array}{l}\text { Volume de água tratada aduzida } \\
\left(\mathrm{m}^{3} / \mathrm{ano}\right)\end{array}$ & & 57.315 .581 & 59.032 .146 & 57.394 .740 & 55.672 .100 \\
\hline $\begin{array}{l}\text { Volume de água faturado } \\
\left(\mathrm{m}^{3} / \mathrm{ano}\right) \text { (3) e }(2)\end{array}$ & 17.731 .500 & 43.070 .000 & 39.978 .800 & 39.514 .600 & 38.113 .100 \\
\hline Volume de esgoto coletado ( $\left.\mathrm{m}^{3} / \mathrm{ano}\right)$ & 41.756 .000 & 39.529 .500 & 52.264 .000 & 38.701 .200 & 32.083 .900 \\
\hline $\begin{array}{l}\text { Volume de esgoto tratado } \\
\left(\mathrm{m}^{3} / \mathrm{ano}\right)\end{array}$ & & & 0 & 0 & 0 \\
\hline Índice de atendimento de água (\%) (1) & 99,0 & 99,0 & 98,0 & 96,0 & 96,0 \\
\hline Índice de atendimento de esgoto (\%) (1) & 96,0 & 97,0 & 96,0 & 96,0 & 93,0 \\
\hline Índice de esgoto tratado( \%) (3) & 0 & 0 & 0 & 0 & 0 \\
\hline $\begin{array}{l}\text { Investimentos no sistema de água } \\
(\mathrm{R} \$ / \mathrm{ano}) \text { (2) }\end{array}$ & 29.397 .000 & 918.000 & 3.245 .216 & 2.137 .750 & 786.935 \\
\hline $\begin{array}{l}\text { Investimentos no sistema de esgoto } \\
\text { (R\$/ano) (1) }\end{array}$ & 4.278 .000 & 6.099 .000 & 303.077 & 356.283 & 451.583 \\
\hline
\end{tabular}

Fontes: (1) Sistema Nacional de Informação sobre Saneamento - SNIS; (2) Instituto Brasileiro de Geografia e Estatística - IBGE; (3) Serviço Municipal de Saneamento Ambiental de Santo André - Semasa.

mentos do Município, levando a crer que, quando os partidos políticos do gestor estadual dos serviços de água e esgoto e do gestor da cidade compartilham com os mesmos ideais, a eficiência e a eficácia da gestão aumentam significativamente.

O Plano Diretor de São José dos Campos apresenta o saneamento básico no capítulo do Planejamento Territorial, o que é uma visão bastante peculiar e interessante, sob o ponto de vista de que o saneamento básico tem um papel fundamental no planejamento. É peculiar também quanto à menção que faz em relação aos programas e projetos prioritários para a política municipal de meio ambiente, dentre eles: programa de controle e tratamento de esgoto doméstico, programa de controle da qualidade das águas.

Ao destacar as diretrizes contidas na Lei Orgânica e no Plano Diretor, cruzando-as com programas, projetos, atividades, obras e metas, e analisando-as do ponto de vista da articulação e integração desses programas entre gestores municipal e estadual, é que foram destacados os pontos na eficiência e na eficácia da gestão em relação aos aspectos de esgoto e de água.
Com relação ao quesito eficiência na gestão estadual dos serviços de água e esgoto de São José dos Campos, a análise foi efetuada de forma um pouco diferente daquela realizada para a gestão municipal, uma vez que não foram disponibilizados Planos que permitissem a identificação de programas, projetos e atividades, provenientes das políticas de governo do órgão gestor desses serviços, que seriam comparados com as diretrizes da Lei Orgânica e do Plano Diretor. Assim, esse quesito foi analisado do ponto de vista da articulação e integração dos programas e projetos estabelecidos pelo gestor municipal em parceria com o gestor dos serviços de água e esgoto, identificados nos orçamentos anuais de São José dos Campos e, também, em entrevistas informais com profissionais da Secretaria Municipal de Economia desse Município. Nesse contexto, a gestão estadual, no aspecto esgoto e água, mostra-se eficiente.

Quanto ao quesito eficácia, tanto no aspecto esgoto, quanto no aspecto água, a análise se deu de forma pontual, ou seja, somente focada nos resultados obtidos pelo questionário, não podendo conside- rar o cruzamento com programas, projetos, obras e metas que o órgão gestor dos serviços de água e esgoto estabelece em seus Planos de Investimentos, pelos motivos já expostos, o que causou um mascaramento em termos referenciais, no momento das conclusões finais aferidas. Desse modo, com relação à eficácia da gestão estadual, no aspecto esgoto, tem-se que: a gestão estadual desse serviço mostra-se e $f$ caz quanto ao atendimento de esgoto por apresentar-se com índice de 99\%, significando que quase toda a população Joanense é atendida com rede coletora. Quanto ao indice de tratamento de esgoto, considera-se que a gestão estadual também é eficaz, pois este índice está em $41 \%$ do que é coletado, como mostra a tabela 3 . O referencial para esta afirmação foi o município de Campinas, que apresenta um índice de tratamento de $10 \%$. Porém, é necessário, ainda, que esse órgão gestor realize maiores investimentos no sistema de esgoto, em conjunto com o órgão municipal no planejamento da cidade, pois, o número de economias ativas de esgoto mostra-se crescente, assim como a população, demandando infra-estruturas para sua sustentabilidade. 
Com relação à eficácia no aspecto água, a gestão estadual mostra-se eficaz, na medida em que, seu atendimento é considerado pela Companhia como $100 \%$. Nesse sentido, os investimentos no sistema de água são para a manutenção do sistema, atendimento ao crescimento vegetativo da população e atendimento aos municípios pertencentes à Unidade de Negócios do Vale do Paraíba. Pode ser observado, também, que o número de economias de água passou de 135.267 para 153.136 , ou seja, 17.869 economias atendidas ao longo de 5 anos, vide tabela 3 . Se considerarmos que cada economia tem 3 pessoas, isso representa um atendimento de 53.607 pessoas. Ao compararmos esse número com o crescimento da população urbana nesse mesmo período, ou seja, de 1996 a 2000, tem-se 50.000 habitantes, concluindo, então, que o órgão gestor desse serviço vem mantendo constante $o$ atendimento ao longo desses 5 anos, o que vem confirmar a eficácia nesse aspecto.
Município de Santos - A gestão dos serviços de água e esgoto é realizada pela Companhia Estadual de Saneamento, de forma indireta, através de concessão.

A Lei Orgânica de Santos tem poucas diretrizes para o saneamento, entre as quais, destacam-se aquelas contidas no artigo 156, que diz que o município consignará, anualmente, no orçamento, percentual para preservação e recuperação do meio ambiente. Assim, foram identificados nos orçamentos anuais, período 1996-2000, programas e projetos voltados ao saneamento básico, mostrando a intenção do governo municipal na articulação e integração com políticas públicas locais. Destaca-se também o artigo $6^{\circ}$ dessa Lei Orgânica, apontando que compete ao município legislar sobre assuntos de interesse local e, nesse sentido, foi identificada nos orçamentos anuais do município a intenção da municipalização do saneamento.

Com relação ao Plano Diretor, as diretrizes estão bastante reduzidas, uma vez que, em Santos, a atualização do Plano é realizada por meio de Lei Complementar e não por Plano Substitutivo. Assim sendo, foi identificada na última Lei Complementar a seguinte diretriz "Promover a extensão da rede de saneamento básico nas áreas urbanas e de expansão urbana”. Desse modo, identificouse nas políticas de governo, projetos para implantação do sistema de captação na Área Continental e para obras de esgotamento sanitário nos morros de Santos.

Ao destacar as diretrizes contidas na Lei Orgânica e no Plano Diretor de Santos, e cruzando-as com programas, projetos, atividades, obras e metas identificados nos orçamentos anuais do município, percebeu-se a ausência de articulação e integração destes programas entre gestores municipal e estadual. Portanto ao destacar pontos na eficiência e na eficácia da gestão em relação aos aspectos de esgoto e de água, considerou-se "sem aferição", para este Município.

Tabela 3 - Informações sobre água, esgoto e população - período de 1996 a 2000

\begin{tabular}{|c|c|c|c|c|c|}
\hline \multirow[t]{2}{*}{ Informação } & \multicolumn{5}{|c|}{ São José dos Campos } \\
\hline & 1996 & 1997 & 1998 & 1999 & 2000 \\
\hline População total (hab.) (3) & 493.029 & 503.867 & 515.198 & 526.651 & 537.899 \\
\hline População urbana (hab.) (3) & 481.265 & 493.293 & 505.871 & 518.639 & 531.275 \\
\hline Economias ativas micromedidas (un.) (2) & 135.267 & 140.936 & 147.601 & 148.577 & 153.136 \\
\hline Economias ativas de esgoto (un.) 2) & & 126.574 & 132.651 & 139.229 & 142.819 \\
\hline $\begin{array}{l}\text { Volume de água tratada produzido } \\
\left(\mathrm{m}^{3} / \mathrm{ano}\right)\end{array}$ & 36.098 .500 & 50.479 .500 & 52.805 .000 & 54.972 .000 & 55.966 .000 \\
\hline Volume de água faturado ( $\left.\mathrm{m}^{3} / \mathrm{ano}\right)$ & 24.199 .500 & 33.142 .000 & 33.637 .000 & 34.360 .000 & 33.028 .000 \\
\hline Volume de esgoto coletado ( $\left.\mathrm{m}^{3} / \mathrm{ano}\right)$ & & 21.644 .500 & 22.358 .000 & 21.908 .000 & 22.199 .000 \\
\hline Volume de esgoto tratado ( $\left.\mathrm{m}^{3} / \mathrm{ano}\right)$ & & & 9.167 .000 & 8.982 .000 & 9.102 .000 \\
\hline Índice de atendimento de água (\%) (1) & & & - & - & 100,0 \\
\hline Índice de atendimento de esgoto (\%) (1) & & & - & + & 99,0 \\
\hline Índice de esgoto tratado ( \%) (1) & - & - & 41,0 & 41,0 & 41,0 \\
\hline $\begin{array}{l}\text { Receita operacional dos serviços de água } \\
\text { (R\$/ano) (1) }\end{array}$ & 24.179 .176 & 27.882 .676 & 32.061 .904 & 32.899 .069 & 35.662 .926 \\
\hline $\begin{array}{l}\text { Despesa operacional dos serviços de água } \\
\text { (R\$/ano) (1) }\end{array}$ & 5.273 .081 & 5.332 .007 & 5.822 .136 & 5.441 .506 & 5.161 .046 \\
\hline $\begin{array}{l}\text { Investimentos no sistema de água } \\
\text { (R\$/ano) (1) }\end{array}$ & 27.111 .900 & 27.049 .800 & 31.358 .600 & 28.906 .600 & 30.822 .500 \\
\hline $\begin{array}{l}\text { Investimentos no sistema de esgoto } \\
\text { (R\$/ano) (1) }\end{array}$ & 29.603 .700 & 29.123 .000 & 15.592 .800 & 13.667 .800 & 15.879 .600 \\
\hline
\end{tabular}

Fontes: (1) Companhia de Saneamento Básico do Estado de São Paulo - Sabesp (2) Sistema Nacional de Informação sobre Saneamento - SNIS; (3) Instituto Brasileiro de Geografia e Estatística - IBGE. 
Com relação ao quesito eficiência da gestão estadual dos serviços de água e esgoto para o Município de Santos, não foi possível proceder à análise de forma similar àquelas realizadas para os Municípios de Campinas e Santo André, uma vez que não foram disponibilizados os $\mathrm{Pla}$ nos contendo programas, projetos e atividades, provenientes das políticas de governo do órgão gestor desses serviços, que seriam comparadas com as diretrizes da Lei Orgânica e do Plano Diretor. Não sendo possível também proceder da mesma forma que aquela realizada para o Município de São José dos Campos, que foi em relação à integração e articulação do gestor da cidade com o gestor dos serviços de água e esgoto, pois não foram encontrados nos orçamentos municipais programas, projetos ou atividades que demonstrassem tais evidências. Portanto, no aspecto esgoto e água, em relação à eficiência na gestão estadual desses serviços para Santos, não foi possível aferir.

Quanto ao quesito eficácia na gestão para os aspectos esgoto e água, procedeu-se à análise pontual, ou seja, somente focada nos resultados obtidos pelo questionário, não considerando o cruzamento com programas, projetos, obras e metas que o órgão gestor dos serviços de água e esgoto estabelece em seus Planos de Investimentos, pelos motivos já expostos, o que causou um mascaramento em termos referenciais, no momento das conclusões finais aferidas. Assim sendo, foi analisada somente a eficácia da gestão estadual em função dos resultados quantitativos fornecidos por aquele órgão gestor.

Desse modo, com relação à eficácia da gestão estadual no aspecto esgoto, temse que: a gestão desse serviço mostra-se eficaz quanto ao atendimento de esgoto por apresentar-se com índice de $95 \%$, significando que quase toda a população santista é atendida com rede coletora. No entanto, esse percentual de $5 \%$ sem atendimento representa em torno de 20.000 habitantes, os quais poderiam ser contemplados com esses serviços se assim for o planejamento do município, pois se percebe que a receita desses serviços é alta se comparada com as despesas e com o investimento no mesmo período (vide Tabela 4).

Quanto ao indice de tratamento de esgoto, considera-se que a gestão estadual também é eficaz, pois este índice está em 95\% do que é coletado, no entanto para fins desta pesquisa foi considerado como "sem aferição", de forma similar ao dito anteriormente para o quesito eficiência.
Com relação à eficácia no aspecto água, a gestão estadual mostra-se eficaz, na medida em que, seu atendimento é considerado pela Companhia como $100 \%$. Assim, os investimentos no sistema de água são para a manutenção do sistema, atendimento ao crescimento vegetativo da população e atendimento a outros municípios da Região Metropolitana de Santos, pertencentes à Unidade de Negócios da Baixada Santista, conforme informação daquela Companhia. Se considerarmos, que a população de Santos manteve-se praticamente constante de 1996 a 2000; que a receita operacional desses serviços é alta em relação aos investimentos, logo, é possível que o gestor estadual atenda, também, áreas de interesse local, em conformidade com as diretrizes do Plano Diretor da cidade buscando assim ter uma cidade saudável.

\section{CONCLUSÃO}

Das políticas públicas estudadas, quais sejam, Constituição Federativa do Brasil de 1988, Política Nacional de Meio Ambiente de 1981, Política Nacional de Saúde de 1990, Política Nacional de Recursos Hídricos de 1997, Constituição do Estado de São Paulo de 1989, Política Estadual de Saneamento de 1992 e Política Estadual de Recursos Hídricos de 1991, depreenderam-se as observaçōes a seguir.

Em relação à Constituição Federal, há que se comentar o artigo 200, e em relação à Política Nacional da Saúde os artigos 6, 17 e 18, onde se indica que o Sistema Único de Saúde-SUS deverá participar da formulação da política e da execução das ações de saneamento básico. Pois bem, ao analisar os planos plurianuais e os orçamentos anuais dos quatro municípios, constatou-se que não existe uma integração das açôes de saneamento básico com as de saúde, na medida em que nos orçamentos referentes às Secretarias Municipais de Saúde e daquelas com intervenções em saneamento básico não foram identificados programas e projetos integrados; pressupõe-se, então, que as açóes entre saúde e saneamento ainda são tratadas de forma sensivelmente desarticuladas.

Já a Política Nacional de Meio Ambiente não traz uma diretriz específica ao saneamento básico, porém contém diretrizes gerais visando à preservação da qualidade ambiental, que, por sua vez, estão intimamente ligadas às questôes do saneamento e da saúde da população, caben- do aos gestores estabelecerem políticas de governo de forma a articulá-las e integrá-las.

Quanto à Política Nacional de Recursos Hídricos, um dos pontos ressaltados é em relação ao instrumento - Planos de Recursos Hídricos que, segundo a lei, serão elaborados por bacia hidrográfica, por Estado e para o país. Eles têm como função básica orientar a implementação da Política Nacional de Recursos Hídricos. Nesta direção, a Política Estadual de Recursos Hídricos de São Paulo está bastante adiantada uma vez que o Plano Estadual foi implementado e já estão em andamento os Planos de Bacias Hidrográicas, que devem estabelecer diretrizes gerais, em nível regional, capazes de subsidiar ações municipais, notadamente as de saneamento e as de conservação dos recursos hídricos das bacias hidrográficas. Assim sendo, constatou-se que os municípios estudados vêm participando dos Comitês de Bacias buscando articulação e integração das políticas públicas e de governo.

No que tange a Constituição Estadual, artigo 216, fala-se que o Estado instituirá Plano Plurianual de Saneamento. A Companhia de Saneamento Básico realiza o seu Plano Plurianual de Investimentos, porém esse não foi disponibilizado para consulta, impossibilitando avançar as discussões sobre as diretrizes dos serviços de água e esgoto, referentes aos municípios de São José dos Campos e Santos, cuja responsabilidade da gestão é do governo estadual.

Em relação à Política de Saneamento Básico, Lei 7750 de 1992, fala-se do Plano Estadual de Saneamento que deve ser quadrienal, com base em Planos Regionais de Saneamento Ambiental, e encaminhado à Assembléia Legislativa para aprovação até o dia 30 de junho do primeiro ano de mandato do governador. Esse Plano é um instrumento necessário para o estabelecimento e implementação dos programas, projetos e atividades de saneamento, para dar visibilidade à gestão e auxiliar na integração das políticas públicas de recursos hídricos, meio ambiente e saúde. Desde a aprovação dessa lei, ou seja, dez anos, ainda não foi dado conhecimento do Plano Estadual de Saneamento, o que leva municípios a estabelecerem suas políticas públicas próprias que, muitas vezes, são desarticuladas das políticas públicas estaduais.

Percebe-se, então, que essas políticas públicas fazem menção de forma direta ou indireta ao Saneamento, cabendo aos gestores as articulações e integraçōes 
Tabela 4 - Informações sobre água, egoto e população - período de 1996 a 2000

\begin{tabular}{|c|c|c|c|c|c|}
\hline \multirow[t]{2}{*}{ Informação } & \multicolumn{5}{|c|}{ Santos } \\
\hline & 1996 & 1997 & 1998 & 1999 & 2000 \\
\hline População total (hab.) (3) & 417.479 & 417.552 & 417.625 & 417.698 & 417.771 \\
\hline População urbana (hab.) (3) & 415.579 & 415.570 & 415.561 & 415.553 & 415.543 \\
\hline $\begin{array}{l}\text { Quantidade de economias de água ativas } \\
\text { micromedidas (un.) (2) }\end{array}$ & 176.580 & 178.323 & 179.575 & 174.431 & 175.971 \\
\hline $\begin{array}{l}\text { Quantidades de economias ativas de esgoto } \\
\text { (un.) (2) }\end{array}$ & 162.874 & 165.704 & 168.438 & 163.693 & 165.469 \\
\hline $\begin{array}{l}\text { Volume de água tratada produzido } \\
\left(\mathrm{m}^{3} / \mathrm{ano}\right) \text { (1) }\end{array}$ & 75.217 .000 & 76.488 .000 & 68.171 .000 & 79.237 .000 & 79.075 .000 \\
\hline Volume de água faturado ( $\mathrm{m}^{3} / \mathrm{ano}$ ) (2) & 31.901 .000 & 42.413 .000 & 44.401 .000 & 41.106 .000 & 41.250 .000 \\
\hline Volume de esgoto coletado $\left(\mathrm{m}^{3} / \mathrm{ano}\right)$ & 28.537 .000 & 29.032 .000 & 30.170 .000 & 28.156 .000 & 28.332 .000 \\
\hline $\begin{array}{l}\text { Volume de esgoto tratado } \\
\left(\mathrm{m}^{3} / \mathrm{ano}\right) \quad(1)\end{array}$ & 28.537 .000 & 29.032 .000 & 30.170 .000 & 28.156 .000 & 28.332 .000 \\
\hline Índice de atendimento de água (\%) (2) & 100,0 & 100,0 & 100,0 & 100,0 & 100,0 \\
\hline Índice de atendimento de esgoto (\%) (2) & 91,0 & 93,0 & 94,0 & 95,0 & 95,0 \\
\hline Índice de esgoto tratado (\%) (2) & 91,0 & 93,0 & 94,0 & 95,0 & 95,0 \\
\hline $\begin{array}{l}\text { Receita operacional dos serviços de água } \\
\text { (R\$/ano) (2) }\end{array}$ & 39.690 .779 & 50.538 .200 & 448.634 .119 & 46.057 .699 & 49.894 .280 \\
\hline $\begin{array}{l}\text { Despesa operacional dos serviços de água } \\
\text { (R\$/ano) (2) }\end{array}$ & $\ldots$ & 3.961 .406 & 1.575 .079 & 1.482 .807 & 1.249 .787 \\
\hline $\begin{array}{l}\text { Investimentos no sistema de água } \\
\text { (R\$/ano) (2) }\end{array}$ & & 5.471 .913 & 3.060 .817 & 1.703 .319 & 5.085 .349 \\
\hline $\begin{array}{l}\text { Investimentos no sistema de esgoto } \\
\text { (R\$/ano) (2) }\end{array}$ & _ & 3.961 .406 & 1.575 .079 & 1.482 .807 & 1.246 .787 \\
\hline
\end{tabular}

Fontes: (1) Companhia de Saneamento Básico do Estado de São Paulo - Sabesp (2) Sistema Nacional de Informação sobre Saneamento - SNIS;

(3) Instituto Brasileiro de Geografia e Estatística - IBGE.

através de seus planos, programas e projetos, de forma a transformá-los em políticas públicas locais, integradas ao planejamento da cidade. Assim é que ao investigar os Planos Plurianuais, Leis de Diretrizes Orçamentárias, Leis Orçamentárias Anuais, Orçamentos Anuais e Planejamentos Estratégicos, e os resultados das políticas dos governos em cada município, foram evidenciadas questôes como existência de integração entre o órgão gestor dos serviços de água e esgoto e o gestor da prefeitura como no caso de Campinas, Santo André e São José dos Campos, o que não foi evidenciado em Santos. Esse fato levou a concluir que, quando os gestores dos serviços de água e esgoto e os gestores da cidade compartilham dos mesmos ideais políticos, a eficiência e a eficácia em termos de gestão tendem a evoluir, pois contam com políticas públicas e políticas de governo articuladas visando dessa forma à universalização dos serviços. De forma contrária a esse exemplo, tem-se o Município de Santos, onde governo estadual e governo municipal não compartilhavam os mesmos ideais políticos, levando a políticas desarticuladas e com interesses difusos entre município e estado. Dentre os interesses difusos cita-se a prática de gestão desses serviços através de subsídios cruzados, que a Companhia Estadual estabelece, para subsidiar outros municípios atendidos pela Unidade de Negócios da Baixada Santista, considerados como deficitários. Esse é o interesse do gestor estadual, pois sendo o Município de Santos autosuficiente em seus sistemas de água e esgoto, os investimentos nesse Município são somente para manutenção dos sistemas e atendimento ao crescimento vegetativo, sendo a maior parte dos investimentos direcionada para outros municípios. Este é um ponto de controvérsia entre governos estadual e local, na medida em que o gestor municipal tem interesse em investir em áreas ainda des- providas desses sistemas. Portanto, quando o gestor da cidade e o gestor estadual dos serviços de água e esgoto compartilham com os mesmos ideais políticos a questão da eficiência e da eficácia na gestão tendem a ações integradas no planejamento da cidade e as diferenças fazemse presentes positivamente, como é o caso de São José dos Campos.

Do estudo realizado, depreende-se que não basta ter somente políticas públicas e de governo articuladas e integradas, mas, também, que elas sejam avaliadas num processo contínuo para aferir a eficácia dos serviços prestados, mediante confrontação com indicadores sociais. Elementos necessários para aferir a eficácia são, ainda, a participação crescente da população nos mecanismos de implementação de políticas públicas.

Para os usuários não importa se a gestão é municipal ou estadual, se é pública ou até mesmo com a participação da iniciativa privada; interessa, sim, se essa 
gestão possibilita água com qualidade, quantidade e universalidade. Importa, sim, se essa gestão possibilita que seu esgoto seja coletado, afastado e tratado garantindo saúde ambiental e humana. Importa também, e principalmente, se essa gestão oferece serviços capazes de atender às necessidades básicas da comunidade, em forma sustentável e de molde a impulsionar o processo de desenvolvimento econômico-social.

Por fim, um dos caminhos para solucionar essa questão institucional é a implementação de uma Política Nacional de Regulação desses serviços, definindose as responsabilidades de cada um dos níveis de governo de maneira que a regulação e o controle sejam atribuídos ao nível nacional, ficando a prestação dos serviços, a cargo do nível local, direta ou indiretamente, público ou público-privado, concedidas ou não. Assim sendo, a forma institucional é relativa, não importando se estadual ou municipal; o que importa é que toda essa política seja conduzida à luz dos princípios constitucionais e legais. Mas, não só; também é importante contextualizar todo este trabalho no quadro da gestão ambiental moderna, segundo a qual eficiência e eficácia se subordinarão aos três requisitos seguintes: que o processo seja economicamente viável; socialmente eqüitativo e ecologicamente prudente.

\section{REFERÊNCIAS}

ASSEMAE - Associação Nacional dos Serviços Municipais de Saneamento Foco no Município. Disponível na página <URL: http://www.asbyte.com.br/ assemae>Acesso em 14 Abr. 2000a.
ASSEMAE-Associação Nacional dos Serviços Municipais de Saneamento. Relação dos municípios associados à Assemae na categoria de serviço municipal de água e esgoto. Jaboticabal. b. [material encaminhado via internet pela Associação]. 2000.

CNS-Conferência Nacional de Saneamento Comissão de Desenvolvimento Urbano e Interior da Câmara Federal - Subcomissão de Saneamento. Relatório síntese da conferência nacional de saneamento. Brasília, 1999.

FUNASA - Fundação Nacional de Saúde. Diagnóstico nacional dos serviços municipais de saneamento. 2a ed, Brasília, 1996

IBGE - Instituto Brasileiro de Geografia e Estatística. Contagem da população-1996. Disponivel na página <URL: http://www.ibge.gov.br. $>$ Acesso em 24 Abr. 2000.

IBGE - Instituto Brasileiro de Geografia e Estatística. Sinopse preliminar do Censo 2000. Disponivel na página em <URL: http:// www.ibge.gov.br. >Acesso em 2002.

JORGE, W.E. A Politica nacional de saneamento pós-64. São Paulo. [Tese de Doutorado FAU/USP], 1987

LIMA, F. Gestão Ambiental e Recursos Hídricos. In: MANUAL DE GESTÃO DO SEMINARIO TÉCNICO SOBRE A GESTÃO DE SERVIÇOS DE SANEAMENTO-1999. Rio de Janeiro: ABES-RJ, p.I-3 a I-47, 2000.

MICHAELIS. Dicionário da língua portuguesa. Disponível na página <URL: http:// www.uol.com.br/michaelis >Acesso em 2002.

MPO-Ministério do Planejamento e Orçamento. Secretaria de Política Urbana. Série Modernização do Setor Saneamento - Diagnóstico do setor: Saneamento: estudo. econômico e financeiro. Brasília, volume 7, 1995.

SNIS-Sistema Nacional de Informações em Saneamento. Diagnóstico nacional dos serviços de água e esgoto-1996. Brasília: SEDU/IPEA, 1997.
SNIS - Sistema Nacional de Informações em Saneamento. Diagnóstico nacional dos serviços de água e esgoto-1997. Brasília: SEDU/IPEA, 1998.

SNIS-Sistema Nacional de Informações em Saneamento. Diagnóstico nacional dos serviços de água e esgoto-1998. Brasília: SEDU/IPEA, 1999.

SNIS-Sistema Nacional de Informações em Saneamento. Diagnóstico nacional dos serviços de água e esgoto-1999. Brasília: SEDU/IPEA, 2000 .

SNIS-Sistema Nacional de Informaçôes em Saneamento. Disponível na página <URL: http:// www.snis.gov.br> Acesso em 2002

Endereço para correspondência:

Rita de Cássia Ogera

Prefeitura Municipal de São Paulo Secretaria Municipal de

Planejamento Urbano - SEMPLA

Departamento de Planos Urbanos

Rua São Bento, 405 - $18^{\circ}$ andar

010 I I-000 São Paulo -SP - Brasil

Tel: (I I) 329I-4903

E-mail: rcogera@usp.br

\section{engenharia sanitária cambiental www.abes-dn.org.br}

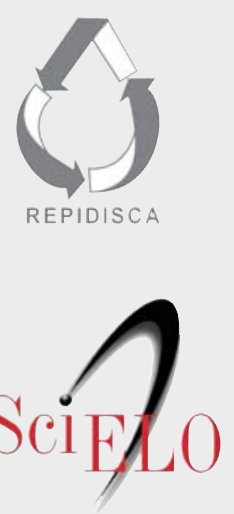

Repidisca - Rede Panamericana de Informaciones en Salud Ambiental http://www.cepis.org.pe

Scientific Eletronic Library Online http://www.scielo.org 